\title{
Rational Design of Dipolar Chromophore as an Efficient Dopant-Free Hole- Transporting Material for Perovskite Solar Cells
}

Zhong'an Li, ${ }^{\dagger}$ Z Zonglong Zhu, ${ }^{\dagger}$ Chu-Chen Chueh, ${ }^{\dagger}$ Sae Byeok Jo, ${ }^{\dagger}$ Jingdong Luo, ${ }^{\dagger}$ Sei-Hum Jang, Alex K.-Y. Jen*广

${ }^{\dagger}$ Department of Materials Science and Engineering, University of Washington, Seattle, Washington, 98195, USA.

\# These two authors contribute to this work equally.

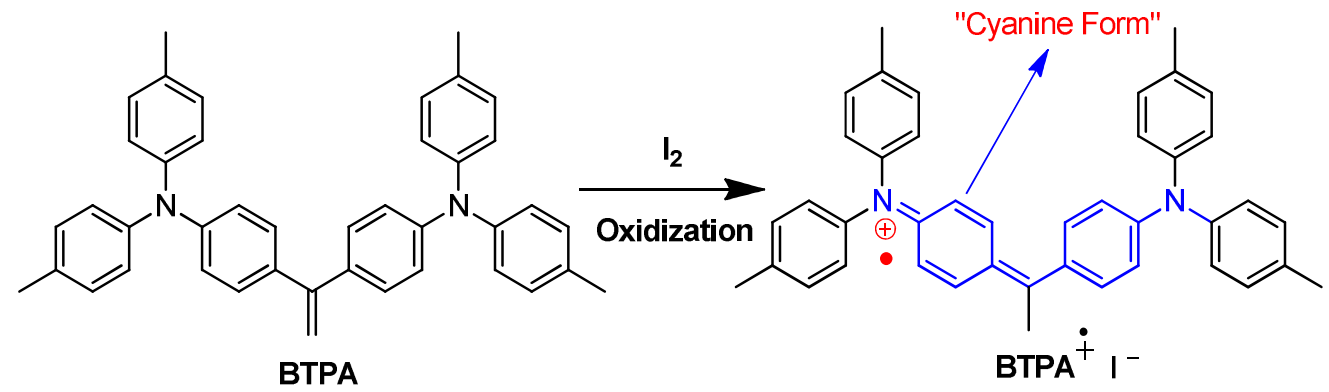

Scheme S1. Chemical oxidization reaction of BTPA by iodine.

Table S1: Crystallographic data of BTPA-TCNE.

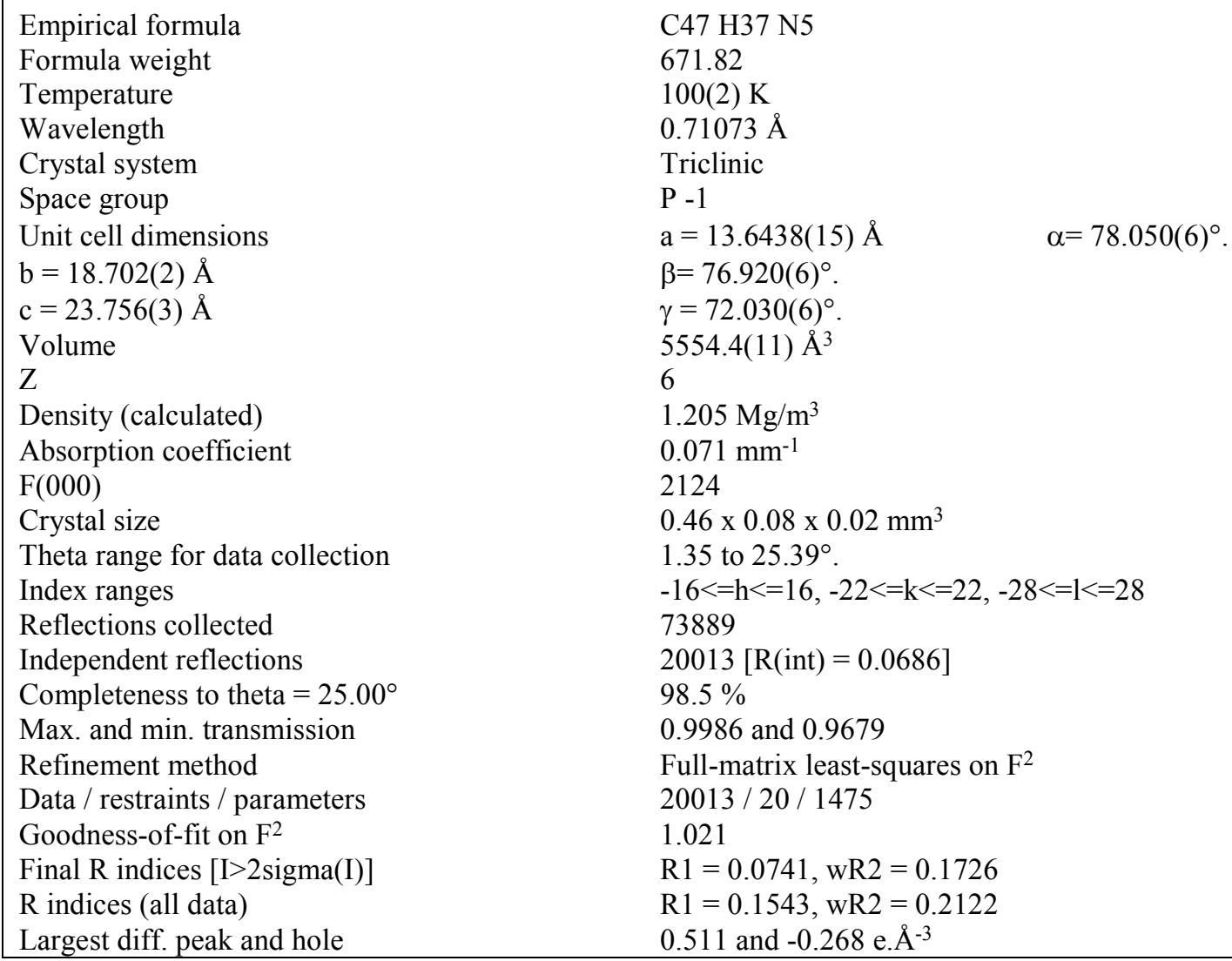


Table S2. Absorption data of BTPA-TCNE.

\begin{tabular}{ccc}
\hline & $\begin{array}{c}\lambda_{\max } \\
(\mathrm{nm})\end{array}$ & $\begin{array}{c}\varepsilon_{\max } \\
\left(\times 10^{5} \mathrm{M}^{-1} \mathrm{~cm}^{-1}\right)\end{array}$ \\
\hline Toluene & 593 & 0.43 \\
THF & 591 & 0.42 \\
DCM & 613 & 0.59 \\
Acetone & 591 & 0.50 \\
DMF & 607 & 0.42 \\
\hline
\end{tabular}

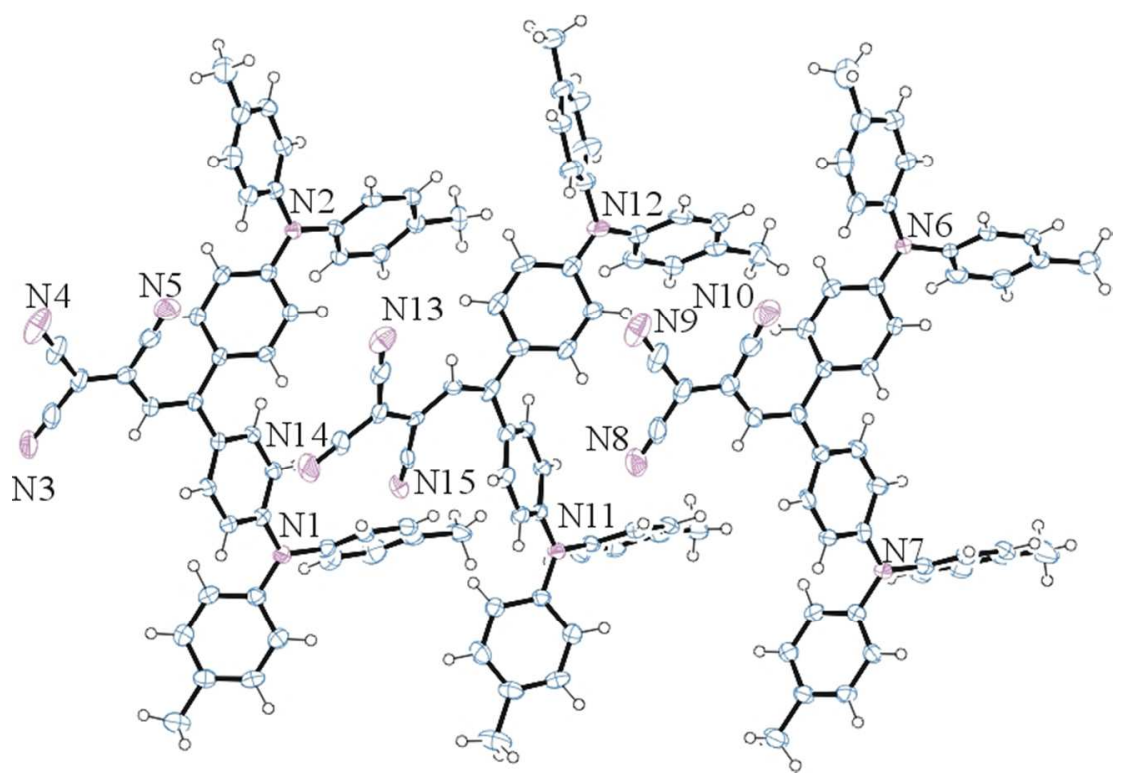

Figure S1. ORTEP of the structure of BTPA-TCNE with thermal ellipsoids at the $50 \%$ probability level. Disorder omitted for clarity. 

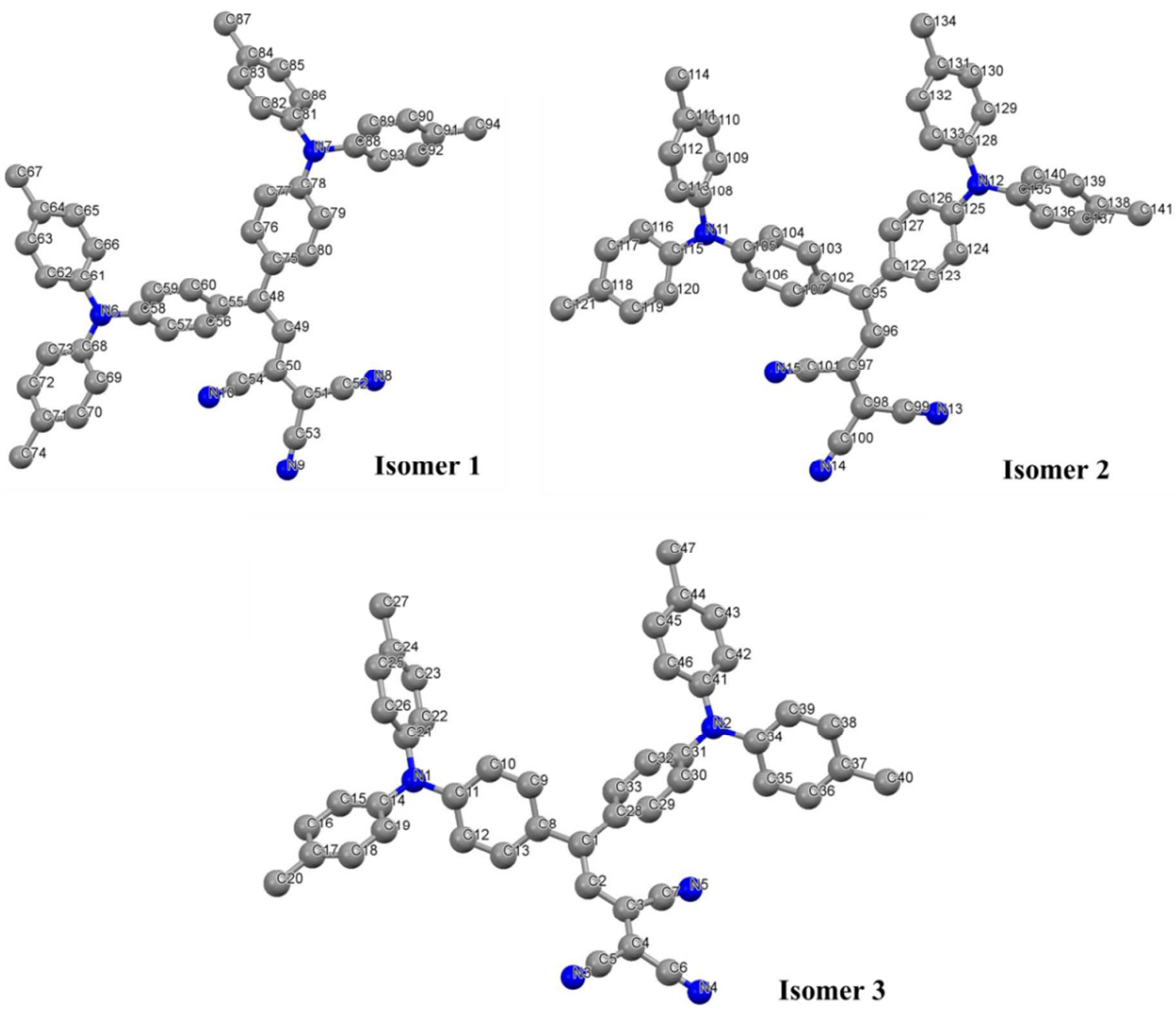

Figure S2. The atomic indices of three isomers in the single crystal structure of BTPA-TCNE, which are used to tabulate the $\mathrm{C}-\mathrm{C}, \mathrm{C}-\mathrm{N}$ bond-lengths.
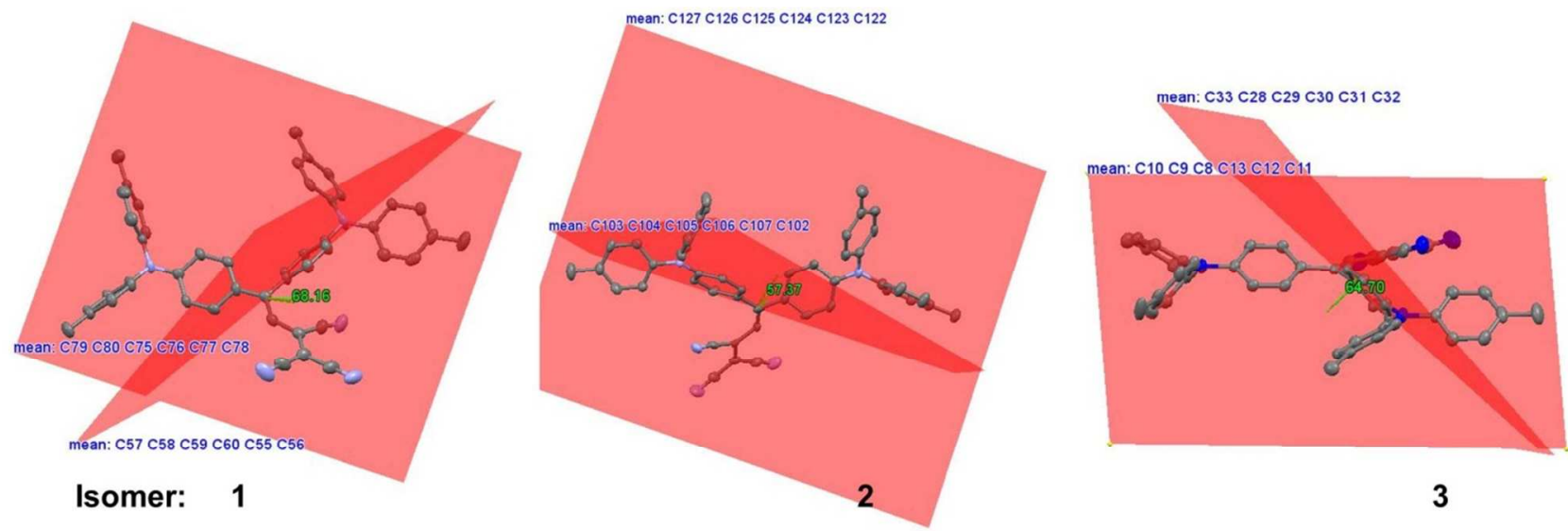

Figure S3. The measured dihedral angles between two triphenylamine units in three isomers for the BTPA-TCNE. The atomic indices are shown in Figure S2. 

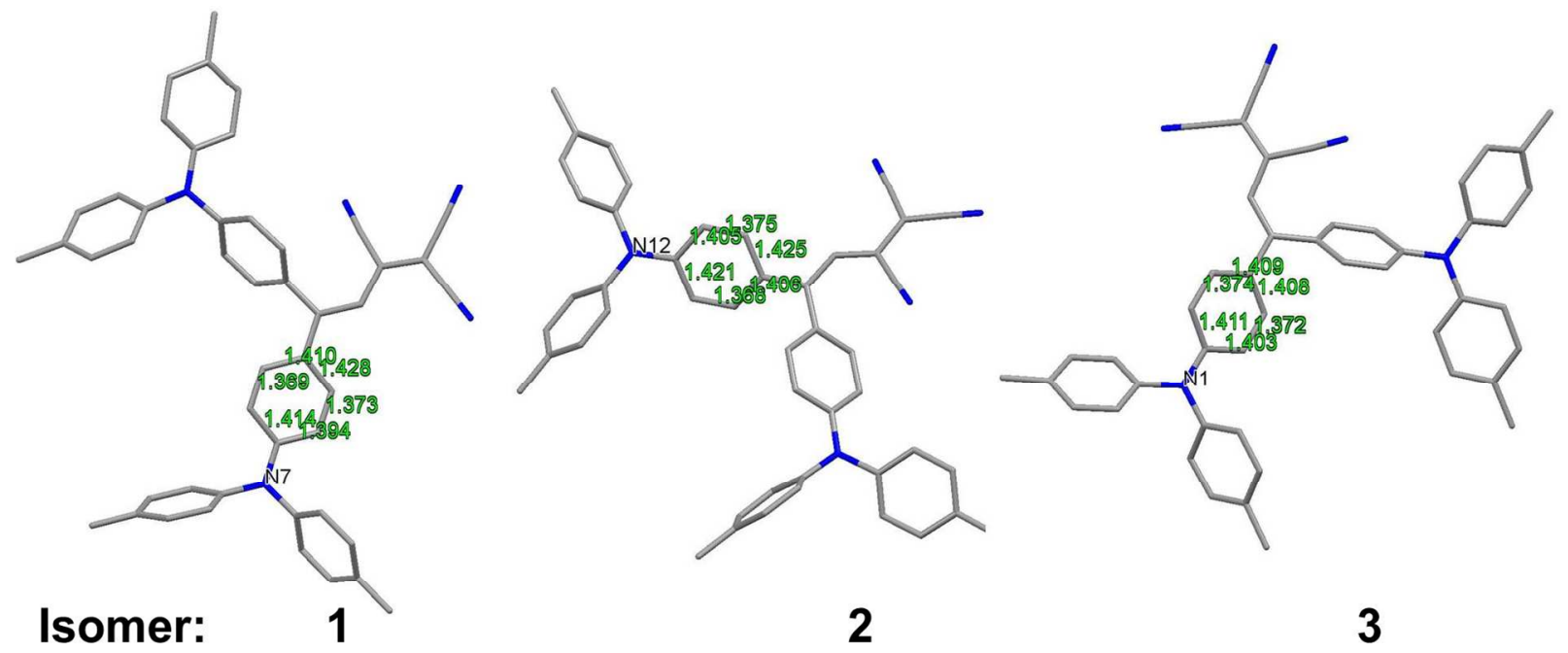

Figure S4. The bond lengths for bridging arylene ring in isomer 1-3.

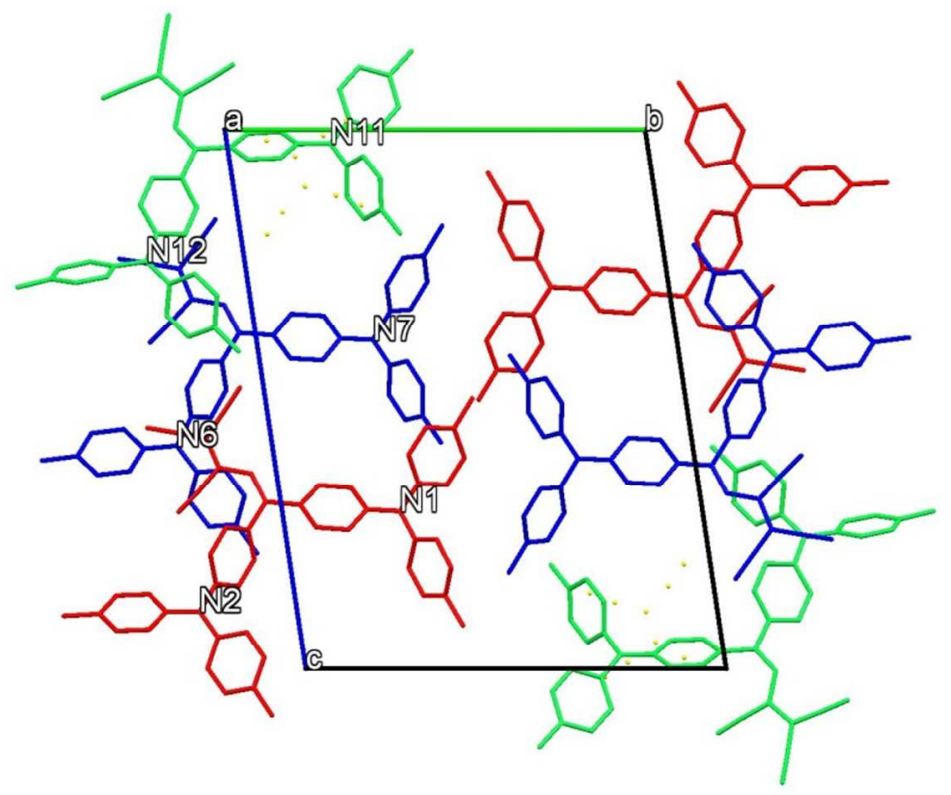

Figure S5. The unit cell of TCTA-TCNE viewed along the $a$ axis. Isomer 1 (blue), 2 (green) and 3 (red). 

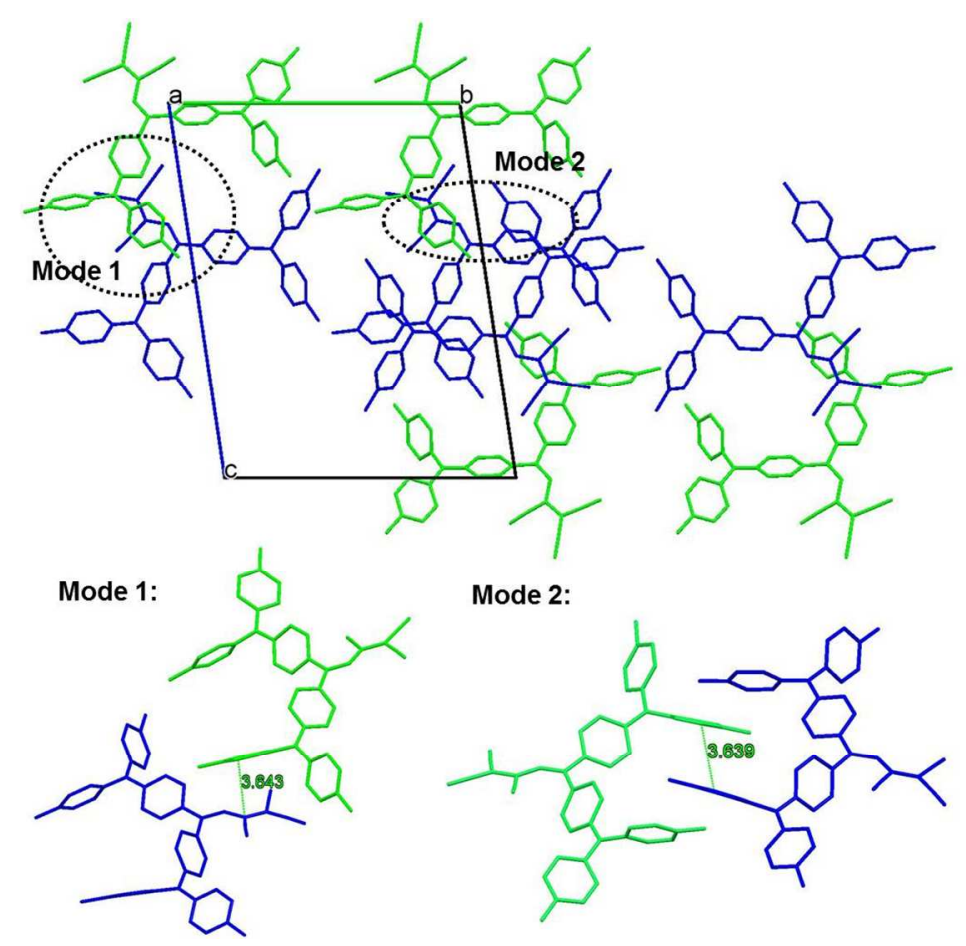

Figure S6. Two molecular packing modes between isomer 1 (blue) and 2 (green) in crystal structure of BTPA-TCNE. For clarity, the hydrogen atoms and isomer 3 are omitted.
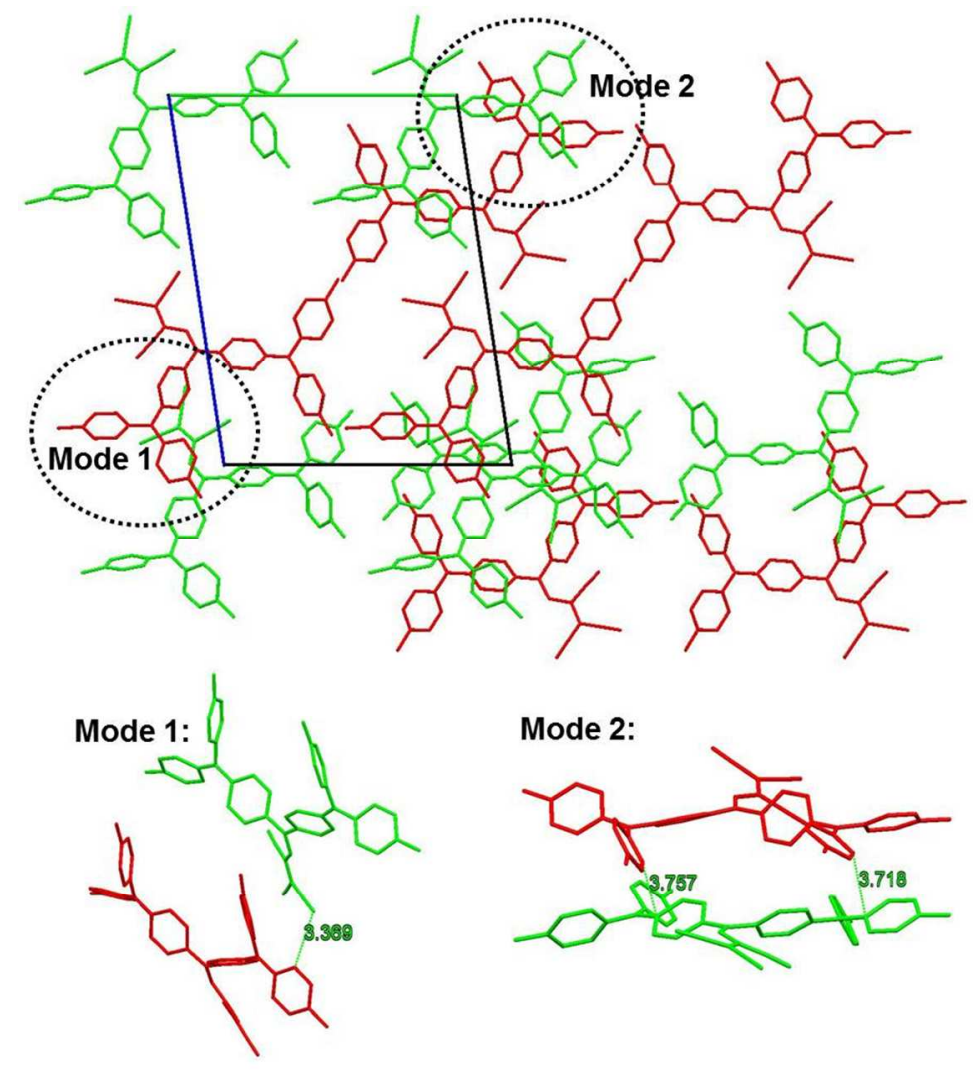

Figure S7. Two molecular packing modes between isomer 2 (green) and 3 (red) in crystal structure of BTPA-TCNE. For clarity, the hydrogen atoms and isomer 1 are omitted. 

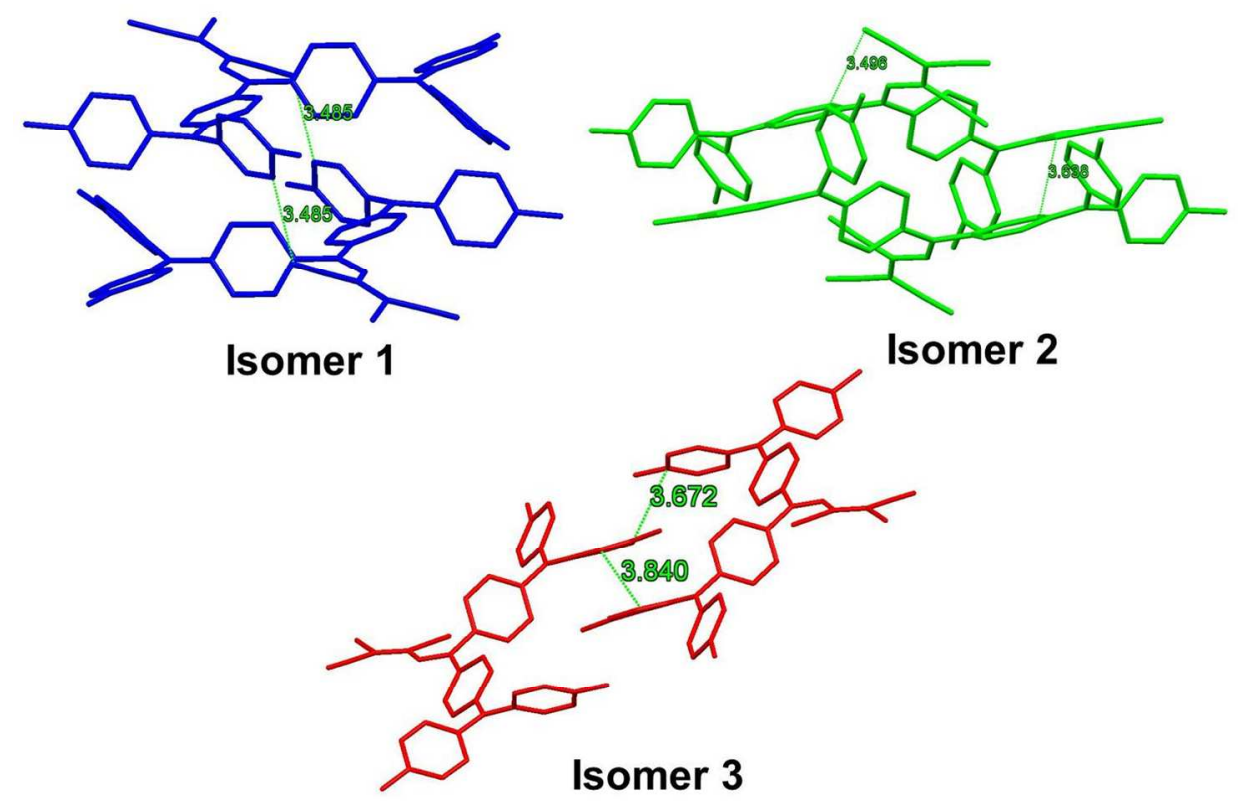

Figure S8. Molecular packing of two same neighboring isomers. For clarity, the hydrogen atoms are omitted.

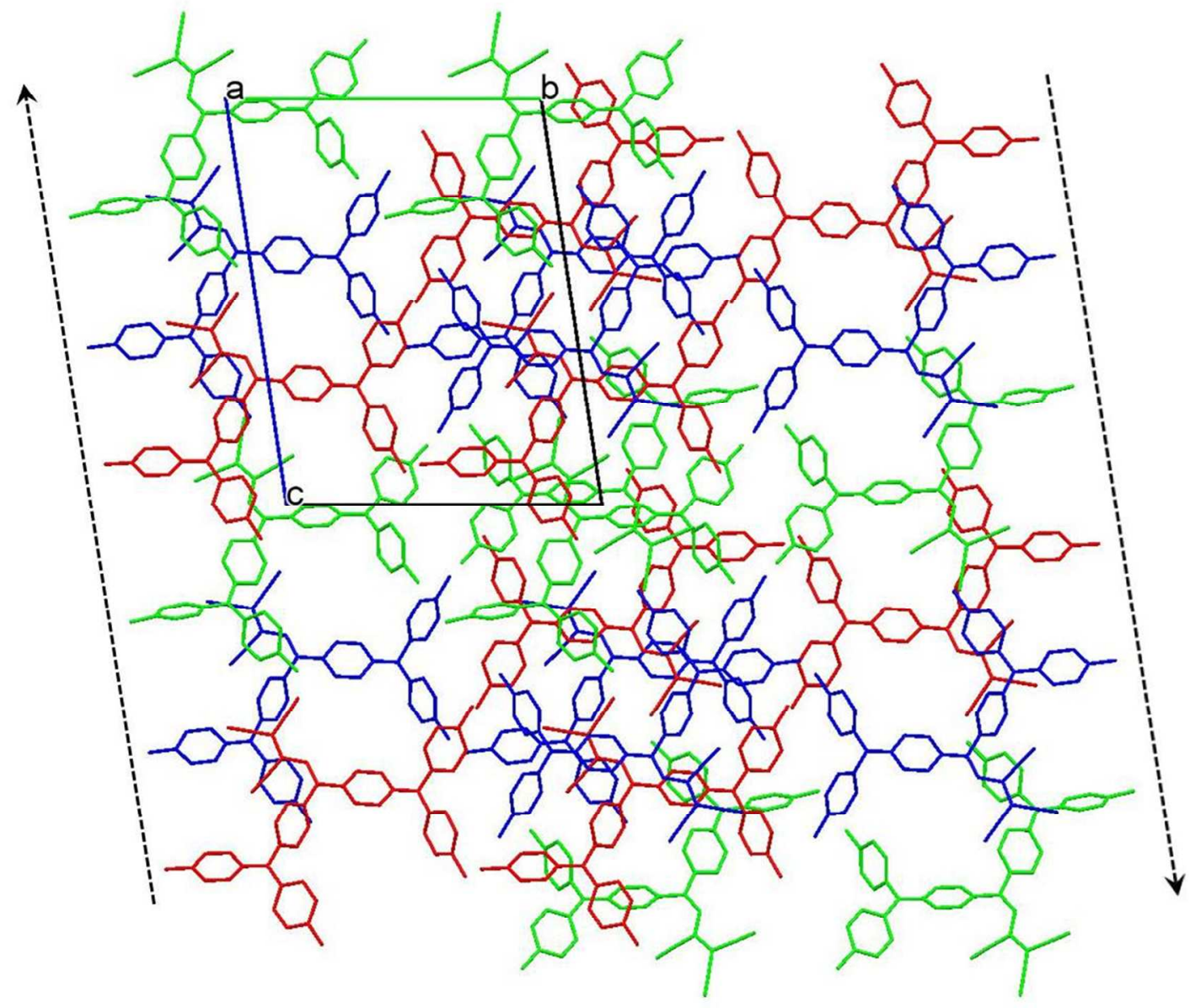

Figure S9. The extended molecular packing of BTPA-TCNE. For clarity, the hydrogen atoms are omitted. 


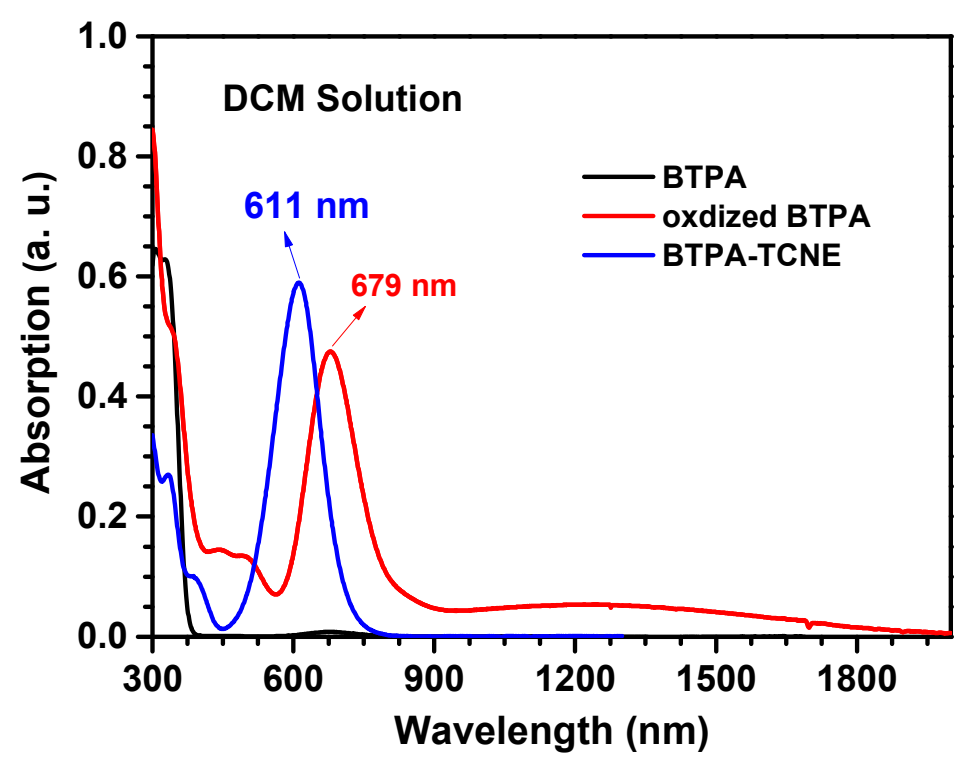

Figure S10. The DCM solution absorption of chromophores. Note: BTPA was oxidized by iodine.

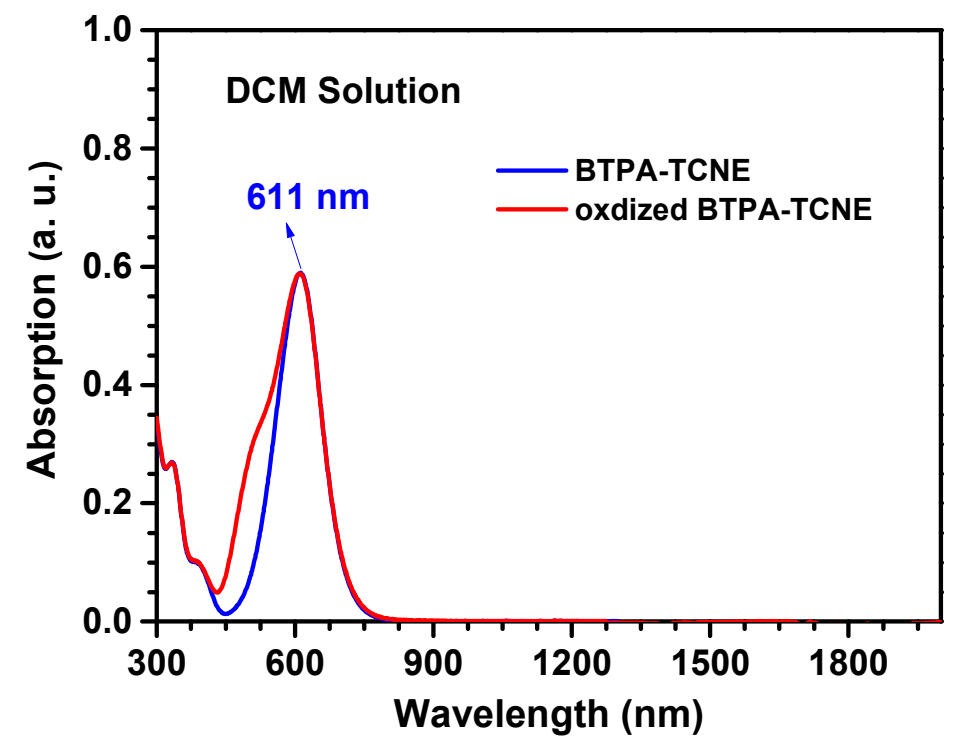

Figure S11. The DCM solution absorption spectra for BTPA-CTNE before and after oxidizing by iodine. 


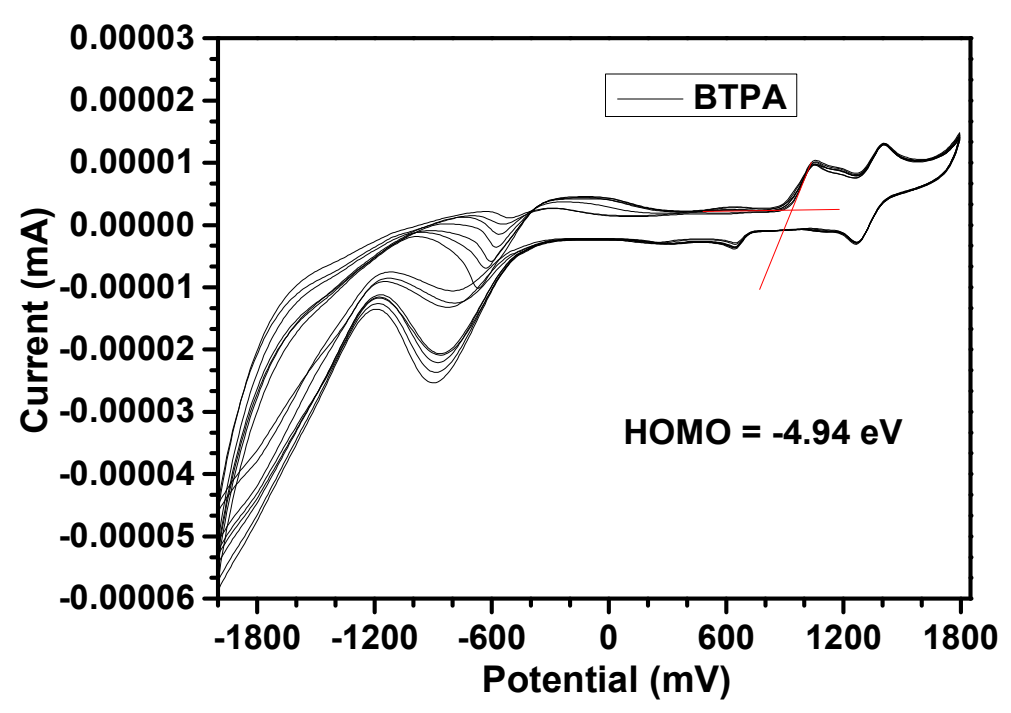

Figure S12. The CV curves of BTPA versus $\mathrm{Fe} / \mathrm{Fe}^{+}(\mathrm{o} .8 \mathrm{~V})$ measured in DCM solution. According to the first oxidization onset, the HOMO level is found to be -4.94 e V. The optical band $\left(E_{\mathrm{Opt}}\right)$ determined by DCM solution absorption spectrum is $3.31 \mathrm{eV}$. Then according to the equation of $E_{\mathrm{LUMO}}=E_{\mathrm{HOMO}}+E_{\mathrm{Opt}}$, the LUMO level is calculated to be $1.63 \mathrm{eV}$. It is noted here, with the increase of scan times, the reduction peak kept changing, which should be due to the electrochemical oxidization.

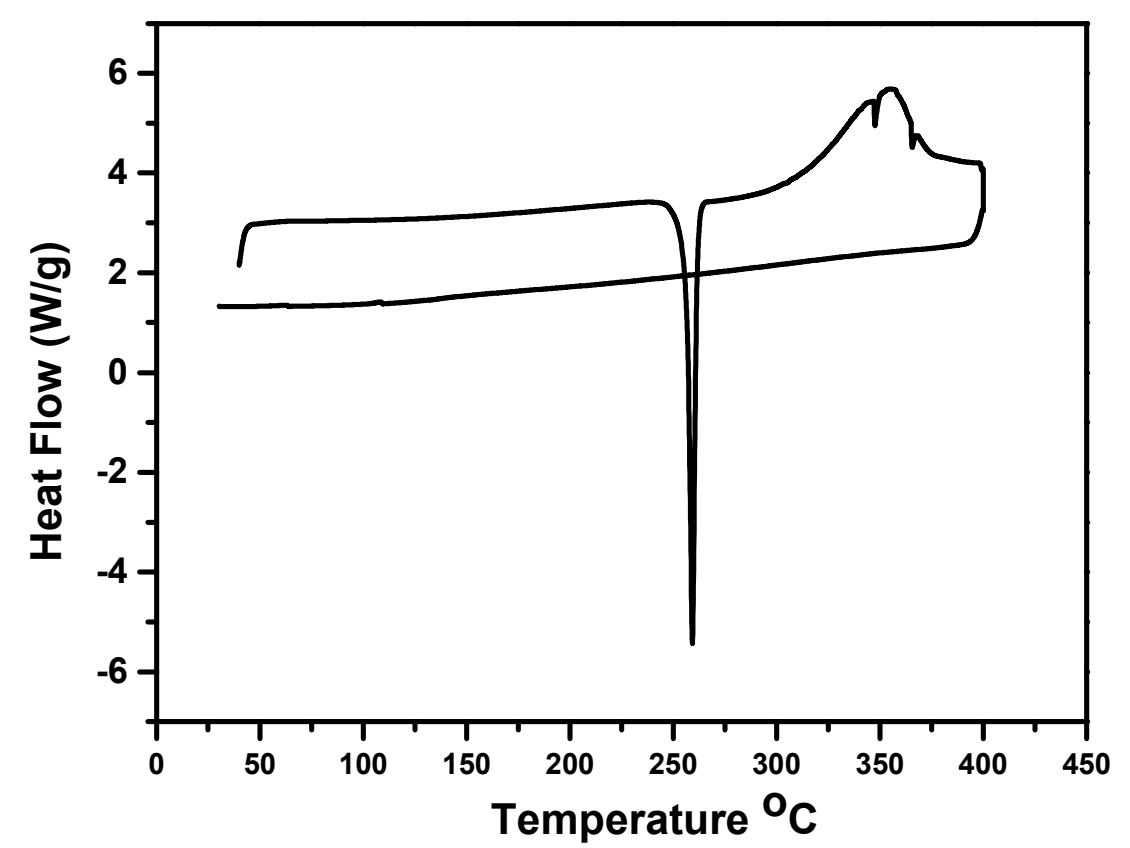

Figure S13. DSC curve of BTPA-TCNE with a scan rate of $10^{\circ} \mathrm{C} / \mathrm{min}$ under nitrogen. 


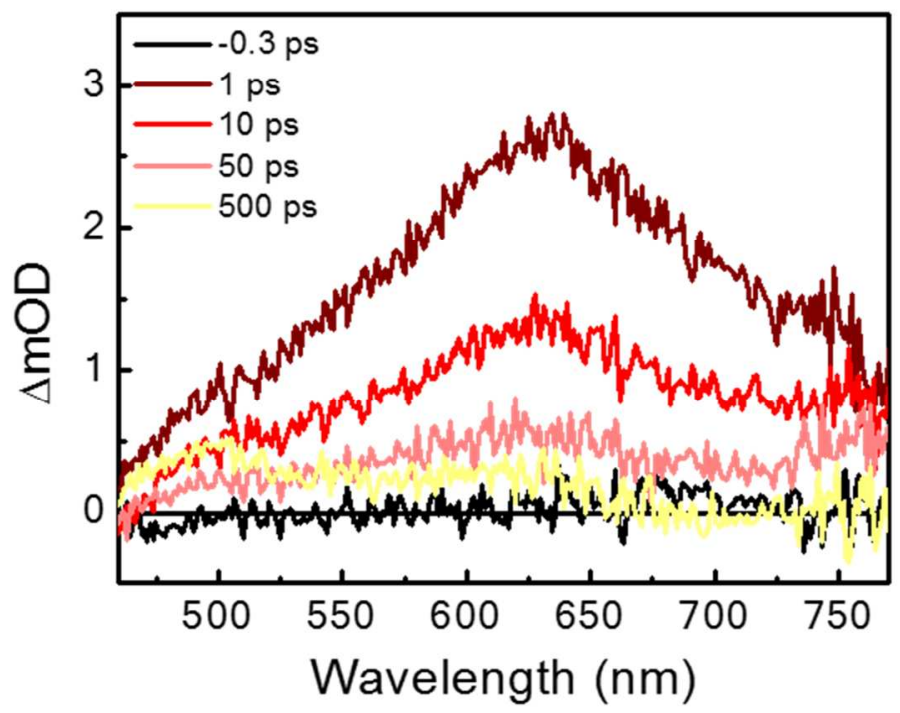

Figure S14. Femtosecond Transient absorption spectrum of BTPA excited at $365 \mathrm{~nm}$.
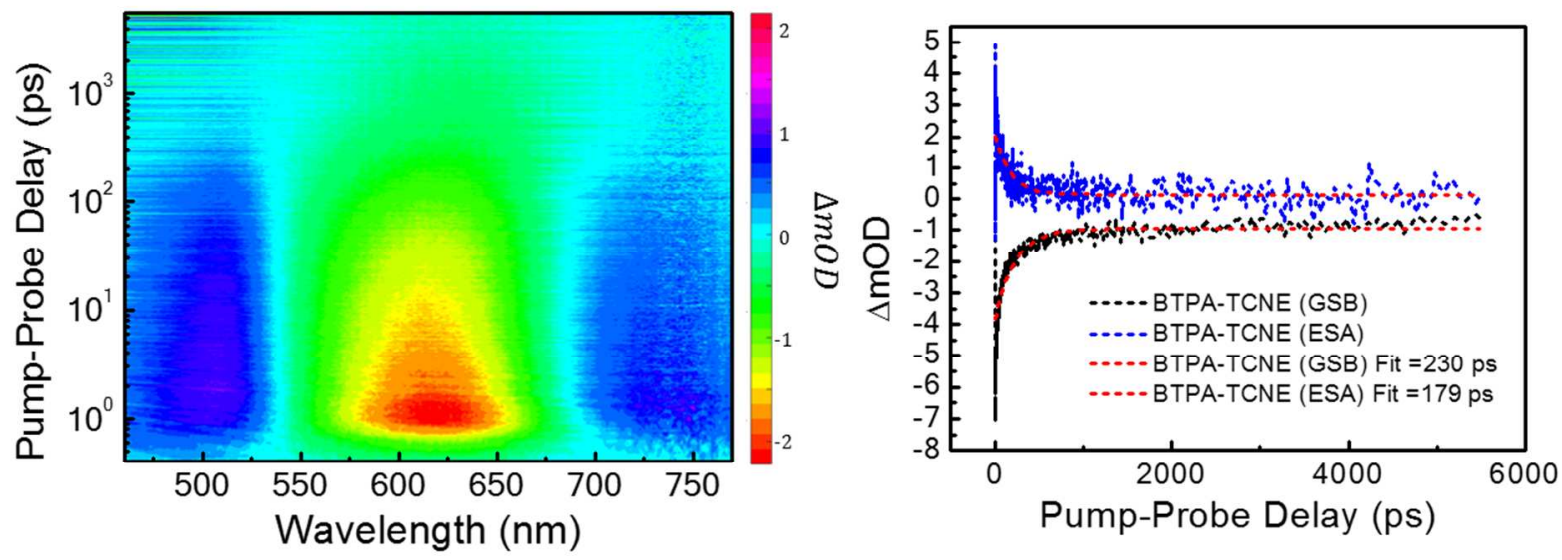

Figure S15. Femtosecond Transient absorption spectrum of BTPA-TCNE excited at $500 \mathrm{~nm}$ (left) and the corresponding decay curves probed at 607 (GSB) and $740 \mathrm{~nm}$ (ESA), respectively. 

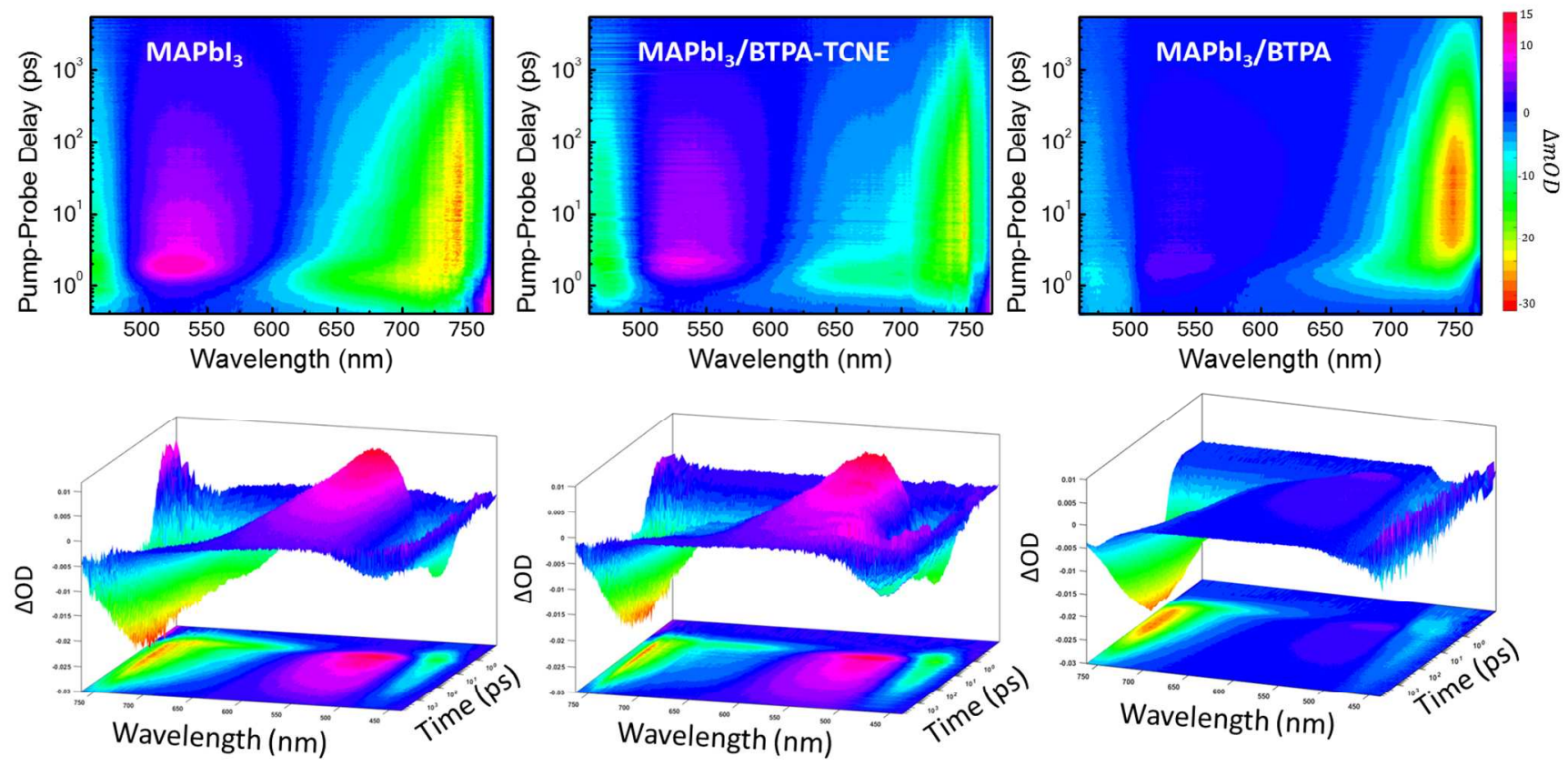

Figure S16. Femtosecond Transient absorption spectra of pristine $\mathrm{MAPbI}_{3}$ film and bilayered $\mathrm{MAPbI}_{3}$ /BTPA-TCNE or BTPA films. Signals were scaled to each absorbance at the pump wavelength.
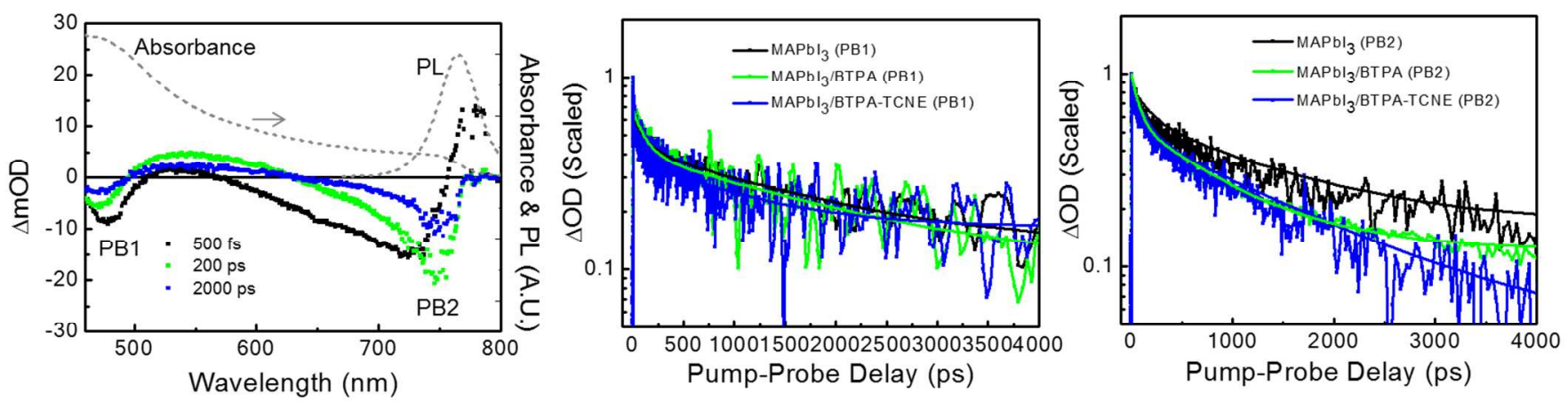

Figure S17. The decay curves of pristine perovskite, and bilayered $\mathrm{MAPbI}_{3} / \mathbf{B T P A}$ and BTPA-TCNE films probed at $466 \mathrm{~nm}$ (PB1). In comparison to the decay of PB2 in the main text, PB1 showed insignificant variations upon introduction of hole transporting layers, which is consistent with previous report. $^{1}$ 


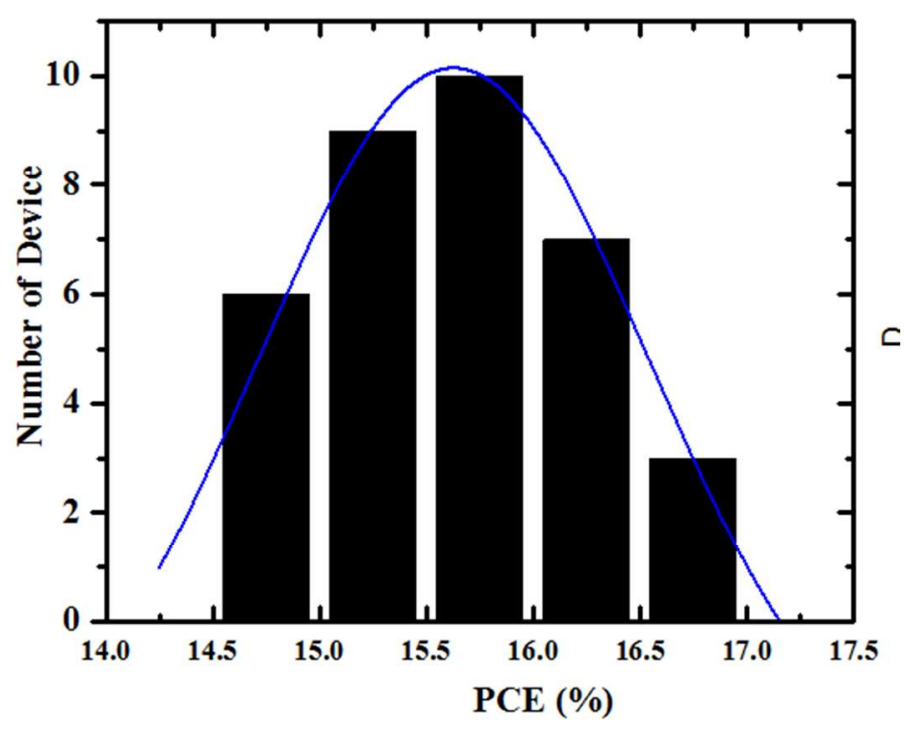

Figure S18. Histogram of efficiency distributions among 35 individual TCTA-TCNE based dopantfree devices.

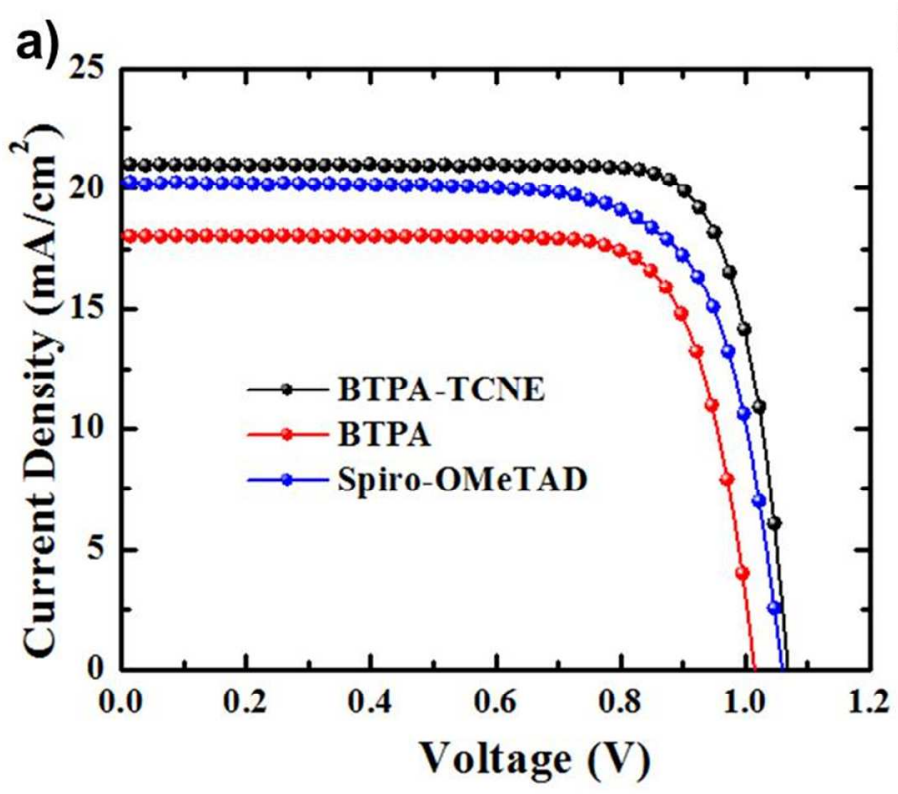

b)

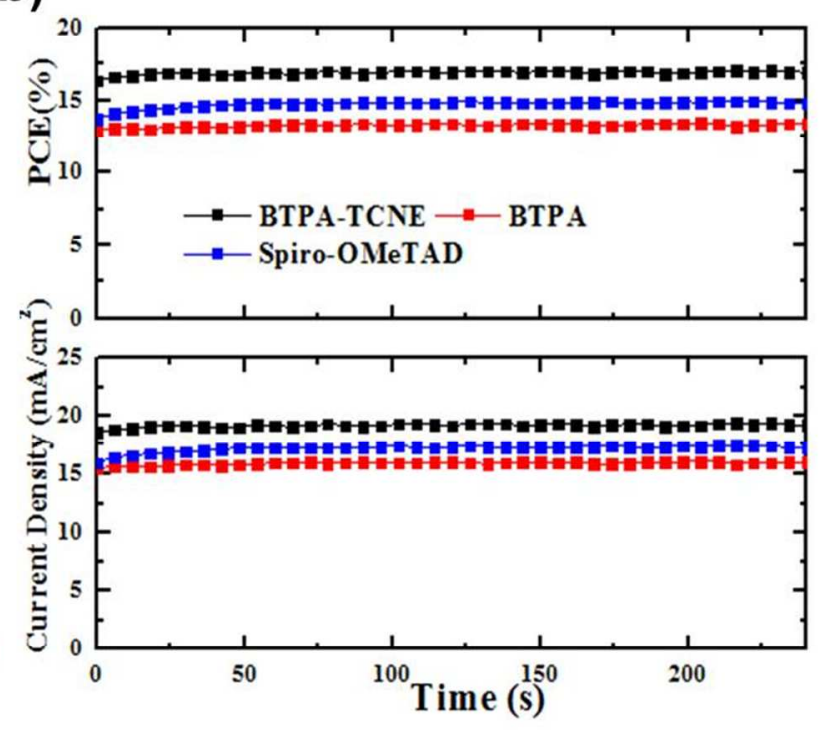

Figure S19. (a) $J-V$ curves of champion PVSCs based on the chemically doped HTMs. (b) The stabilized PCE and photocurrent density obtained while holding the cells near the maximum power point voltage at $0.88 \mathrm{~V}$ (BTPA-TCNE), $0.83 \mathrm{~V}$ (BTPA), $0.86 \mathrm{~V}$ (spiro-OMeTAD). 


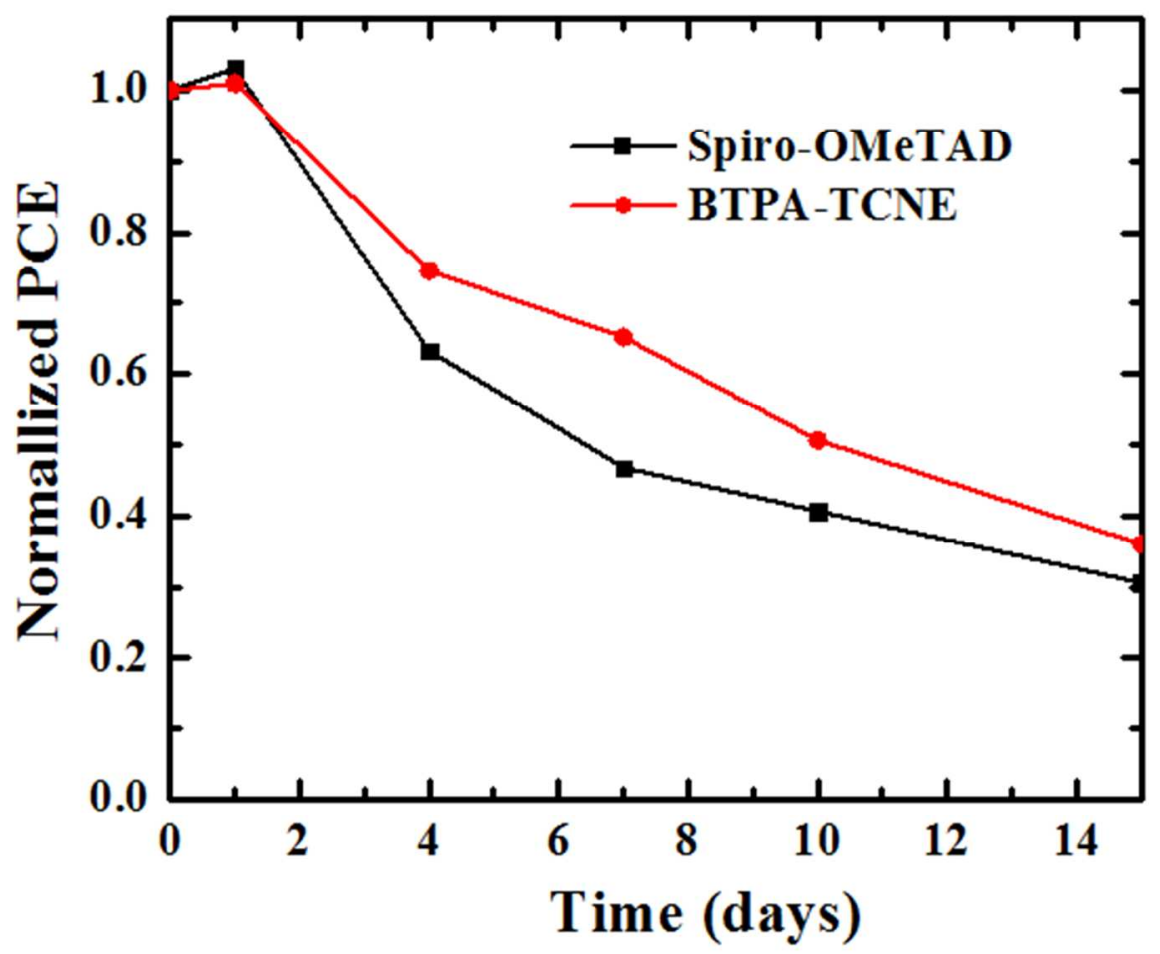

Figure S20. The stability test of the PVSCs using dopant-free BTPA-TCNE and doped spiroOMeTAD as HTL as a function of storage time in air with a controlled humidity of $40 \%$. All $J \sim V$ curves measurements are test in the nitrogen box. 

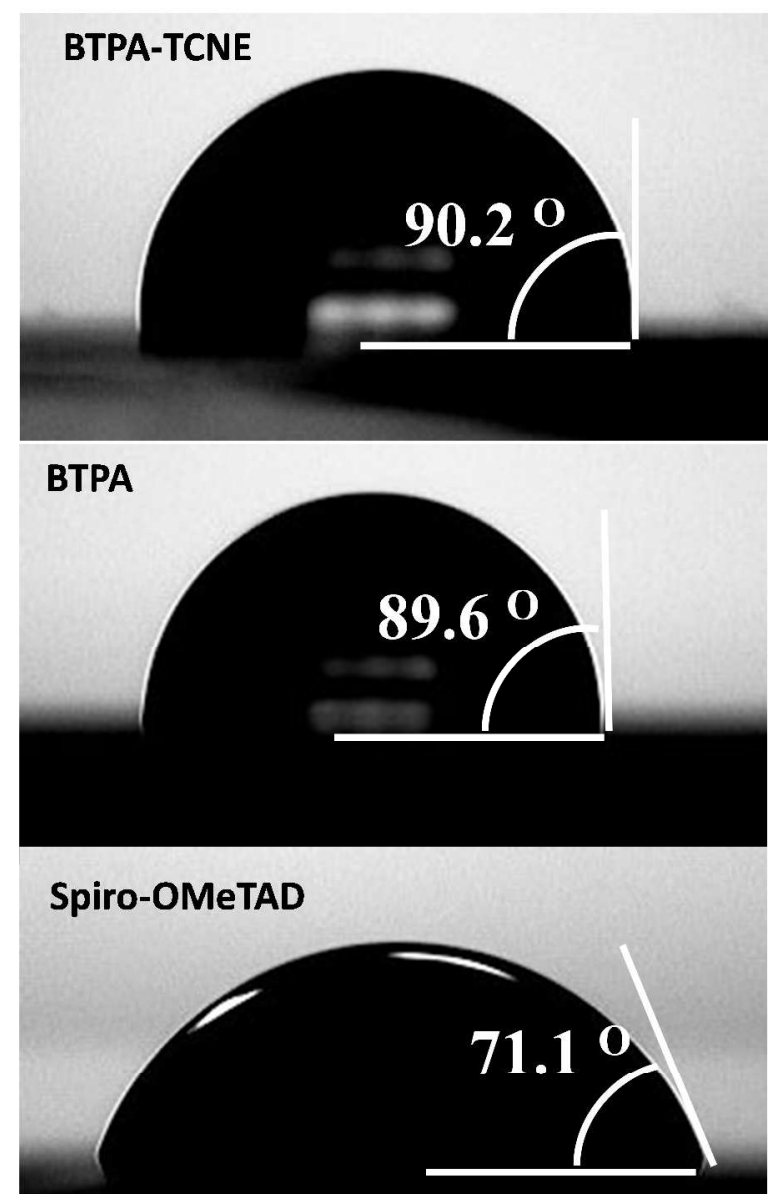

Figure S21. Water contact angles on TCTA-TCNE, BTPA and spiro-OMeTAD. 


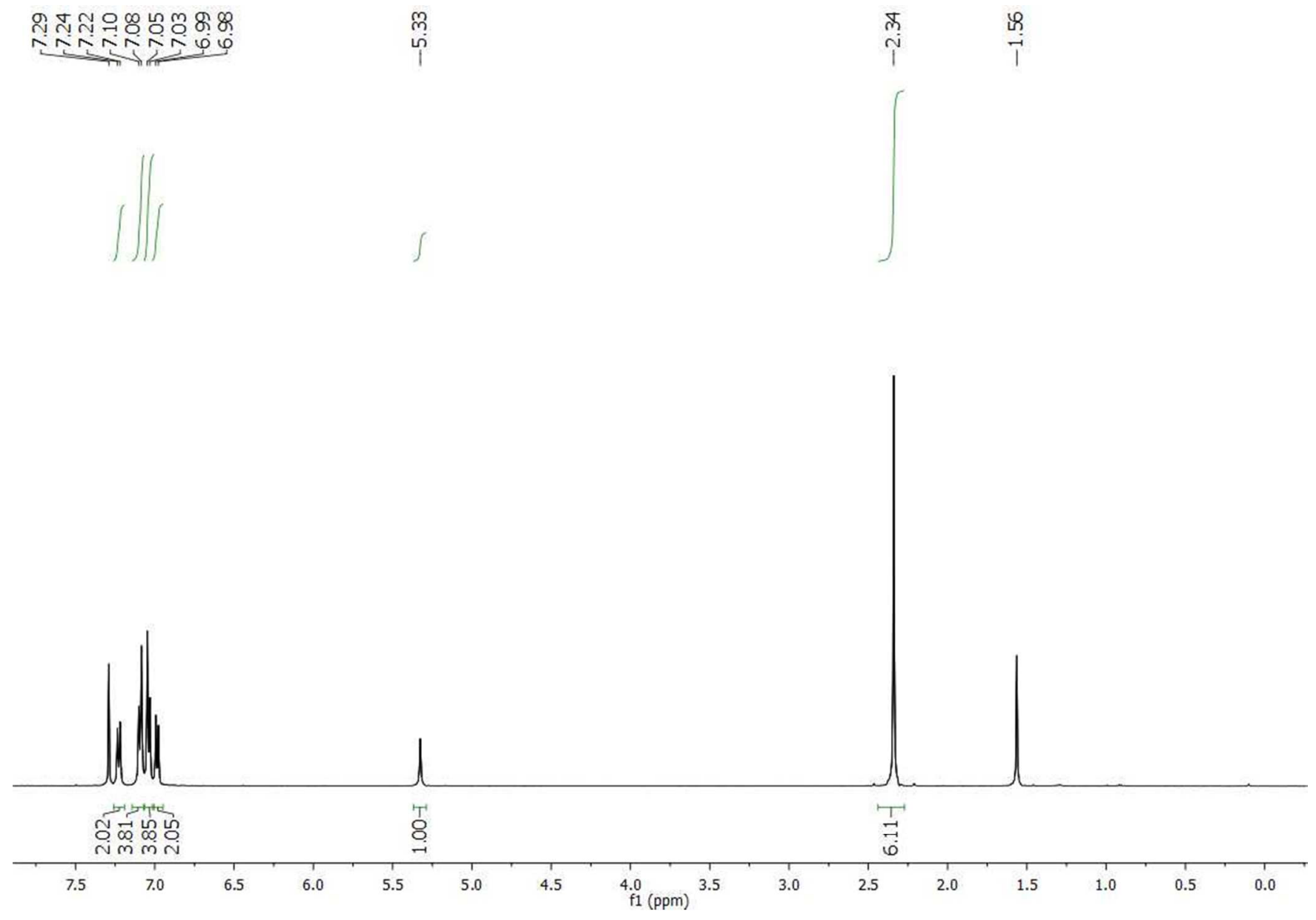

Figure S22. The ${ }^{1} \mathrm{H}$ NMR spectrum of BTPA, conducted in Chloroform- $d_{6}$. 


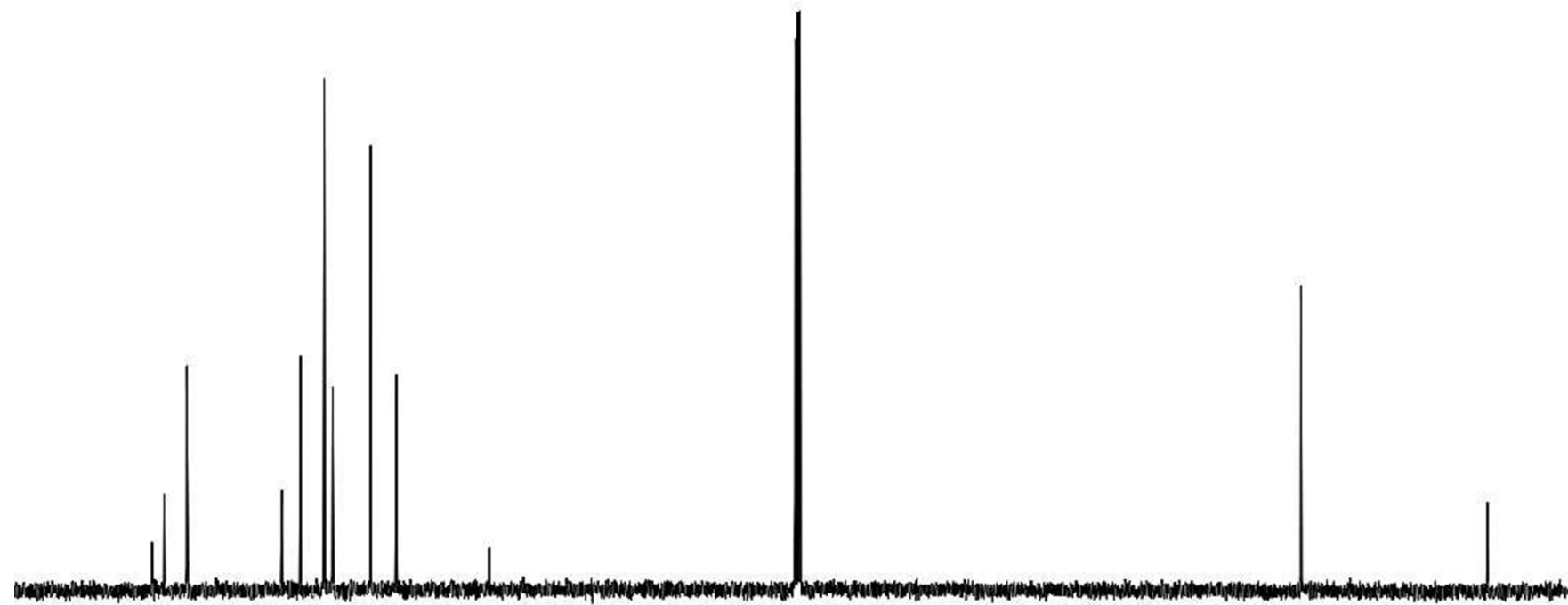

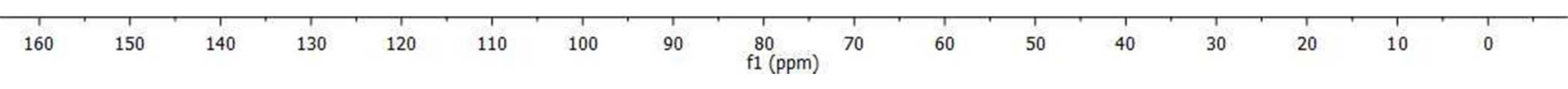

Figure S23. The ${ }^{13} \mathrm{C}$ NMR spectrum of BTPA, conducted in Chloroform- $d_{6}$. 

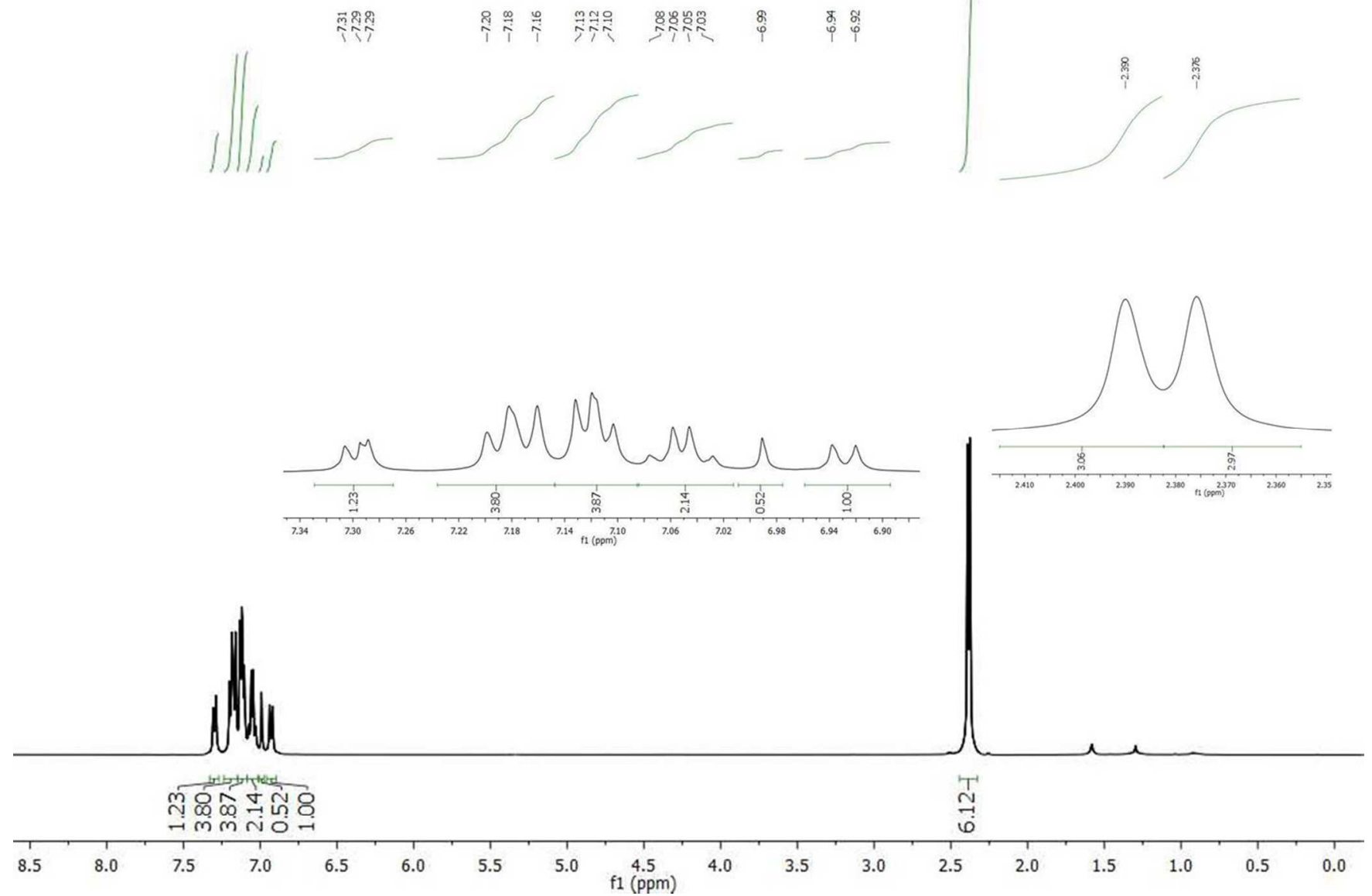

Figure S24. The ${ }^{1} \mathrm{H}$ NMR spectrum of BTPA-TCNE, conducted in Chloroform- $d_{6}$. 


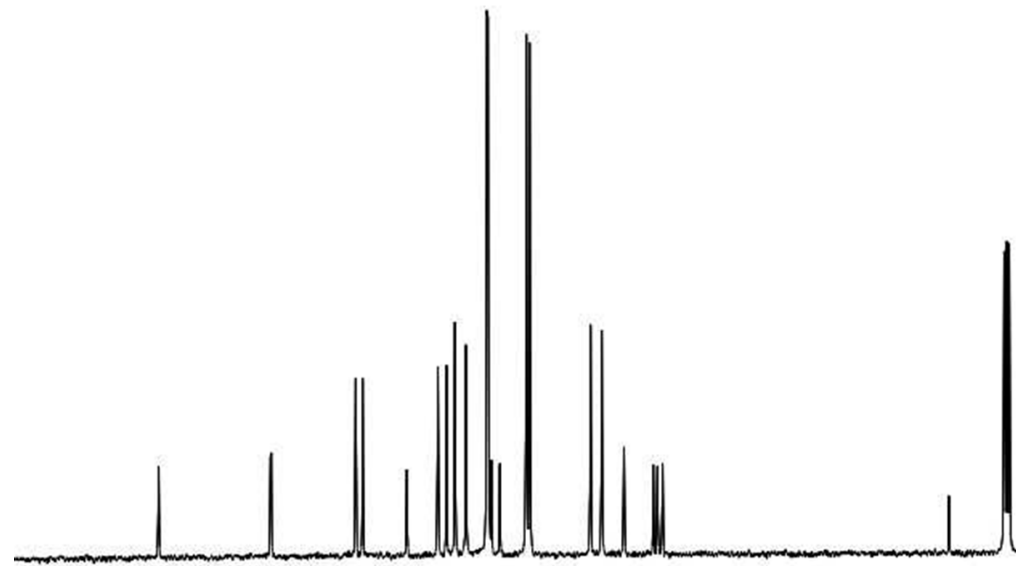

\begin{tabular}{llllllllllllll}
\hline 170 & 160 & 150 & 140 & 130 & 120 & 110 & 100 & 90 & 90 & 1 & 1 & 1 & 1 \\
$\mathrm{f1}(\mathrm{ppm})$ & 80 & 70 & 60 & 50 & 40 & 30 & 20 & 10 & $\mathrm{C}$
\end{tabular}

Figure S25. The ${ }^{13} \mathrm{C}$ NMR spectrum of BTPA-TCNE, conducted in Chloroform- $d_{6}$. 


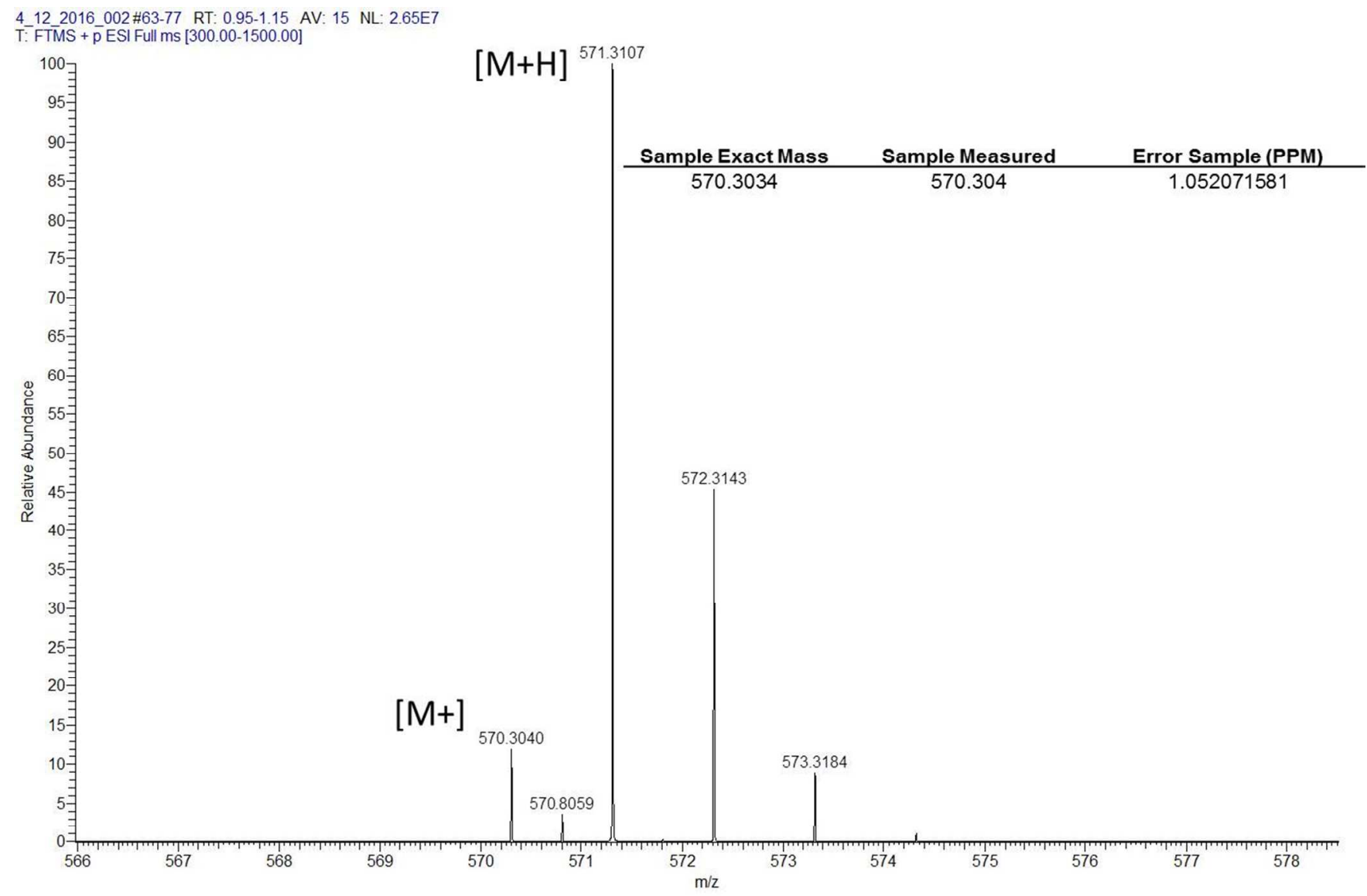

Figure S26. The HR-MS spectrum of BTPA. 


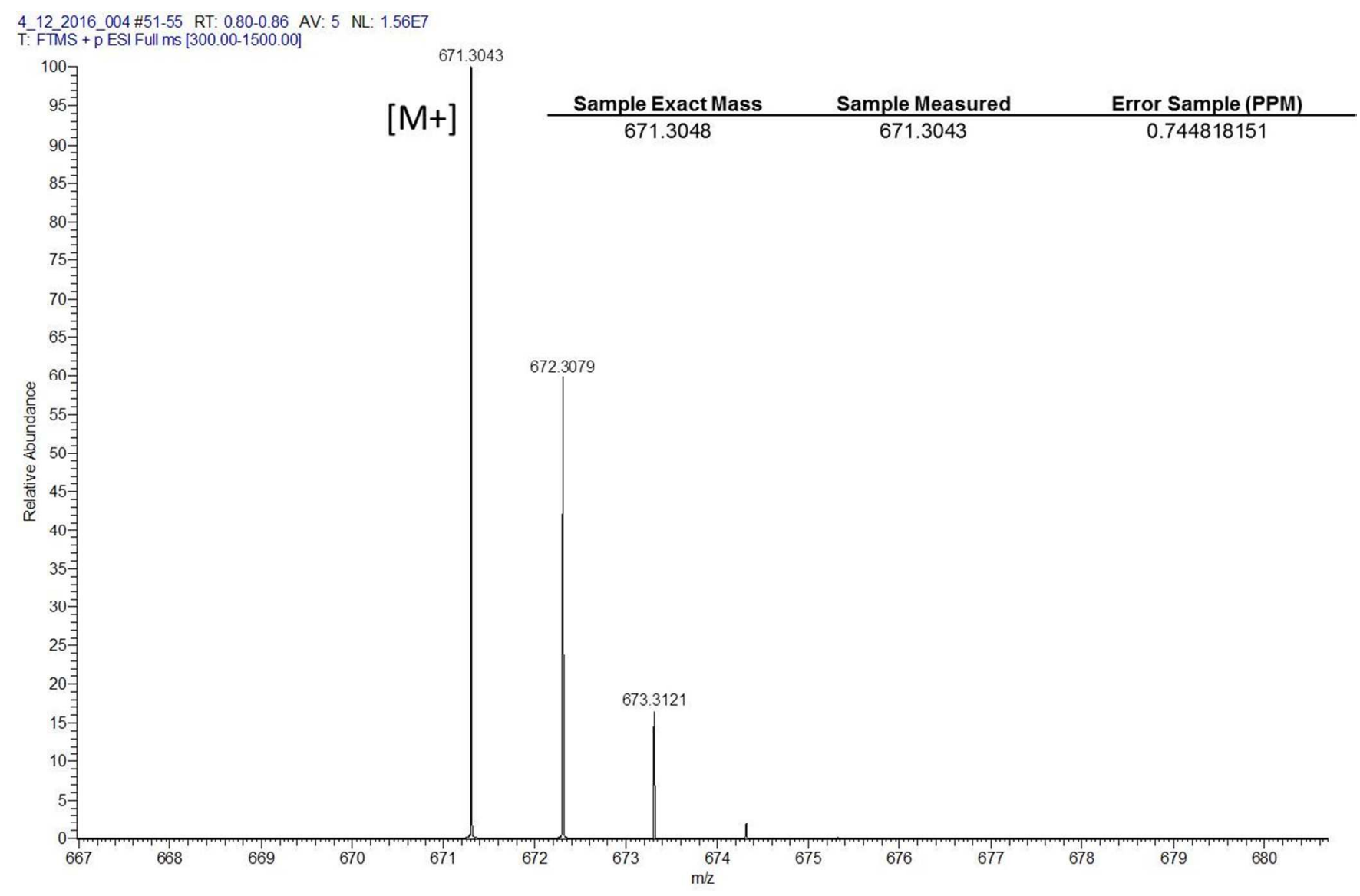

Figure S27. The HR-MS spectrum of BTPA-TCNE.

\section{Reference:}

(1) Xing, G.; Mathews, N.; Sun, S.; Lim, S. S.; Lam, Y. M.; Grätzel, M.; Mhaisalkar, S.; Sum, T. C. Science 2013, 342, 344. 